rotates the four-point pen to the appropriate position before each reading is recorded.

At intervals throughout the exhibition, recitals were given on the Gregorian electronic organ, which is manufactured by Alfred E. Davies and Sons, Ltd., and the Acoustical Manufacturing Co., Ltd. This organ was designed to imitate as closely as possible the tone of a good pipe organ. The basic tone generators are valve oscillators. Special attention has been paid to the 'attack' problem, and variable delays can be introduced to simulate the speaking characteristics of various pipes. One of the most attractive features from the organist's point of view is that the tone colour of any particular stop is governed by a plug-in unit. This means that changes in specification or in the precise quality of any particular stop can be made quite simply even after installation is complete.

Among the measuring equipment displayed by Marconi Instruments, Ltd., the moisture meter was of particular interest. The basic circuit is an ingenious modification of the Wheatstone bridge, which makes the instrument independent of valve characteristics and voltage variations. It is designed to give reliable results without laboratory conditions and without demanding special skill on the part of the operator. Interchangeable scales and calibrations are available for a long and fascinating list of materials, ranging from alginic acid through groundnuts to vermicelli (plain and egg). Another interesting item was a universal bridge for measuring resistance, inductance and capacitance which is really direct reading; the figures on the dial change when the range is changed, and the precise units in which the quantity is being measured also appear on the dial.

Twentieth Century Electronics, Ltd., exhibited precision cathode-ray tubes in which the screen face was ground and polished inside and outside. Also on this stand were a bewildering variety of Geiger counter tubes. Interesting members of the series were a sterilizable tube for medical applications and a tube with a mica window so thin that, when delivered by air transport, it has to be sealed in a metal can to prevent explosion arising from the lowering of atmospheric pressure.

The exhibition was obviously the result of much hard work both by the organizing committee and by the exhibitors; but the very large number of visitors must have been a very satisfying reward for those concerned.

C. A. TAYLOR

\section{DAMPIER : PIRATE AND NATURALIST}

\section{BY DR. L. HARRISON MATTHEWS \\ Director, Zoological Society of London}

W ILLIAM DAMPIER, the pirate whose tercentenary fell on June 8 , is famed as a buccaneer, navigator, diarist and traveller; but his prowess as a naturalist is less well known. His careful descriptions of his travels around the world between 1673 and 1700, which enjoyed considerable popularity in their day and had run into a seventh edition by 1729 , contain many accounts of the wild animals that he came across.

In the day-to-day accounts of his voyages there are frequent notes about the birds, fishes, insects and other animals that he saw, often with interesting opinions on their gastronomic value. But it is in his descriptions of the countries he visited and their inhabitants and products that he really excels and provides us with some excellent chapters on natural history.

He made many trips to the Bay of Campeachy, cutting logwood and buccaneering, that is, making boucan, a sort of biltong prepared by sun-drying the flesh of wild cattle, and his account of his journey in 1676 gives many pages to the fauna of the region. The first animal he mentions is the "squash", which appears to be the coati-mondi. It is bigger than a cat, and its head is much like a fox's with short ears and a long nose. "The flesh of it is good, sweet, wholesome Meat. We commonly skin and roast it; and then we call it Pig ; and I think it eats as well.' He gives a splendid account of the spider monkey, "the ugliest I ever saw. They are much bigger than a Hare and have great Tails about two and a half foot long". When he met a company of them in the woods they defied him by bombarding him with sticks and more offensive ammunition, "chattering and making a terrible Noise ; and a great many grim Faces, and shewing Antick Gestures". He gives details of the prehensile tails of these monkeys, and tells how one old male came on to a small branch just over his head and "leaping directly at me made me start back; but the Monkey caught hold of the Bough with the tip of his 'Tail ; and there continued swinging to and fro, and making Mouths at me".

The great ant-eater has a tongue "like an Earthworm about five or six inches long" with which it licks up ants, and then "puts it out again to trapan more. They smell very strong of Ants, and taste much stronger ; for I have eaten of them". The sloth, "a sad coloured Animal", feeds on the leaves of trees, and takes eight or nine minutes to move one of its limbs three inches; "neither will stripes make them mend their pace . . . they seem insensible, and can neither be frightened, or provoked to move faster".

So his descriptions go on, through the mammals, birds, reptiles and fishes, with some interesting bit of acute observation about each, from the large snakes that are "a lazy sort of Creatures" that "lirk in Trees" to the alligator that bit the knee of Daniel the Irishman and left the marks of its teeth in the butt of his gun; poor Daniel "went limping ever after".

Even in those far-off days of the late seventeenth century, Dampier protested against the reckless slaughter of animals for commercial purposes. $\mathrm{He}$ was particularly concerned for the introduced cattle that had run wild in the West Indies, and were so important to the buccaneers. "The Spaniards pick and chuse only the Bulls and Old Cows, and leave the young Cattle to breed; by which means they always preserve their stock entire". But the English and French "kill without distinction; yea, the young rather than the old; without regard to keeping up their stock". The seals of the West Indies were similarly exterminated; there may be a few West Indian seals alive to-day, but they are among the rarest of mammals. Dampier relates how a sealing crew was wrecked on the Alcrane Islands "distant from the coast of Jucatan about 25 Leagues; the biggest is not above a Mile or two in Circuit". By great good fortune the sealers were able to fill their casks with seal oil, and refloat their ship at the expense of two New England ketches that ran on the reef, misled by the lights of their fires. 
The smaller and more inconspicuous animals did not escape Dampier's notice, for he tells of the two sorts of land crab, the white and the black; "black Crabs are commonly fat and full of Eggs; they are also accounted the better Meat, though both sorts are very good". He also knew Limulus, the primitive horse-shoe crab. Near Campeachy "in the Surf of the Sea, close by the shore, you find abundance of Shell-fish, called by the English, Horse Hoofs, because the under part or Belly of the Fish is flat, and somewhat resembling that Figure in shape and Magnitude; but the Back is round like a Turtles; the Shell is thin and brittle, like a Lobsters; with many small Claws: and by report they are very good Meat; but I have never tasted of them myself. . . . Here are also a sort of Spiders of a prodigious size ... they have two Teeth, or rather Horns an Inch and a half, or two Inches long ... black as Jet, smooth as Glass, and their small end sharp as a Thorn. These Teeth we often preserve. Some wear them in their 'Tobacco pouches to prick their Pipes. Others preserve them for Tooth-Picliers".

In the account of his voyage to Australia or "New Holland" in the Roebuck in 1699, Dampier gives even fuller details of the natural history, the birds, beasts, and especially the fishes, and also of the plants that he found. He illustrates many of these in copper plates that, considering the times, are remarkably good. Many of the species are quite easily identified from his sketches, and it could well be claimed that he was one of the first traveller-naturalists.

As is only natural, Dampier gives the colours of the birds and other creatures that he saw, and his descriptions are correct; yet one may doubt whether his colour perception was complete. When he was at 'Tonquin he saw the galleys of the king's navy which were commanded by a general who "was a great Mandarin. ... There were two more great Officers under him, each in a Vessel by himself. These three had Flags of distinction: the first was yellow, the second blue, the third red or green". Can it be that Dampier was colour-blind, and could not distinguish red from green?

\section{BRITISH MYCOLOGICAL SOCIETY PLANT PATHOLOGY FIELD DAY}

$\mathrm{T}$ HE twenty-sixth annual plant pathology field day of the British Mycological Society was held on July 4 in the Mycology Section of the Hawthorndale Laboratories, Bracknell, Berkshire, of Imperial Chemical Industries, Ltd. Sixty-six members attended.

Mr. R. V. Tipler, senior mycologist, reviewing the functions of the laboratories, stated that the main task was the evaluation of chemicals produced in the research departments of I.C.I. manufacturing divisions for possible use in controlling crop diseases, pests and wastage caused by bacteria, fungi, insects and eelworms in agriculture, horticulture and industry. The Mycology Section was concerned with prevention or control of plant diseases and crop wastage and with industrial microbiological problems. The demonstrations were arranged to illustrate the scope of the Section's activities in the field of bioassay. They showed the sequence of testing from first-stage sorting by in vitro methods for general antifungal and antibacterial activity to second-stage sorting by in vivo methods in laboratory, glasshouse and field to discover applications for promising chemicals in industry and as seed, soil and foliage fungicides. Consolidation work, not capable of being shown at the Laboratories, followed under practical conditions at home and overseas with selected materials, under control of the research staff.

Miss M. E. Kennedy demonstrated methods of maintaining the culture collection. In order to reduce subculturing and minimize possible variations in reactions of test fungi to chemicals or pathogenicity to plants the mineral oil and freeze-drying methods of preservation were used. The former was more suitable for mycelial and non-sporing forms and consisted of culture on agar slopes covered to a depth of $1 \mathrm{~cm}$. above the medium with a sterilized mineral oil. In the latter, suspensions of fungal spores $\mathrm{Or}^{2}$ bacteria, with a protective colloid, were dried in vacuo from the frozen state. Standard reference cultures had been preserved unchanged in the characteristics under study for more than four years. The Hawthorndale method of inducing profuse sporulation of Alternaria solani was demonstrated. Controlled ultra-violet irradiation of mycelial cultures on agar reliably produced spores within eighteen hours. The method had been in regular use for three and a half years.

Mr. J. L. Charlton showed agar plate and spore germination techniques for in vitro screening of chemicals. The first method, based on serial dilution of chemicals in an agar medium which was then inoculated with a range of fungi or bacteria, rapidly placed new chemicals in activity categories. Active chemicals were investigated more precisely by the second method, using spores of Alternaria solani, Venturia incequalis or Botrytis allii. This method was particularly suitable for investigating groups of related chemicals and effect of formulation on antifungal activity. An auxanographic method of demonstrating interactions between effects of chemicals on fungi was on view. Morphological effects of chemicals on germinating spores of Botrytis allii were also shown.

Mr. J. N. Turner had on view the miniature kiln test permitting quantitative comparison of chemicals for control of timber sap-stain and moulding, as used for second-stage evaluation of potential industrial fungicides. Notable features were the use of paired surfaces for treatment versus control comparisons and the high degree of replication achieved within a small space. Tests were seen in progress comparing the British Standards and the Pechmann--Schaile methods for laboratory evaluation of timber preservatives. Mycelial mat and soil burial methods for assessing textile preservatives were shown, together with investigations on the effect of leaching and weathering on degree and duration of proofing. Species of fungi responsible for moulding and staining of baled rubber were exhibited.

Miss S. E. Parkinson illustrated with specimens and cultures of the microflora isolated from them the extent and types of damage to leathercloths caused by micro-organisms.

Types of slimes encountered in paper mills were shown, with cultures of bacteria and fungi responsible for their production. Efficiency of control by organomercurial compounds depended, inter alia, upon the stock, as its composition affected both the type of slime and the absorption and inactivation of mercury by the pulp. Techniques demonstrating bioassay of active mercury in pulp and white-water included two plate methods using Cladosporium herbarum and a turbidimetric method using Lactobacillus helveticus. 